\title{
СЕМАНТИЧЕСКАЯ СТРУКТУРА ПОЛИСЕМАНТОВ «СÆР / ГОЛОВА»И «ЗÆРДÆ / СЕРДЦЕ» В ДИГОРСКОМ ВАРИАНТЕ ОСЕТИНСКОГО ЯЗЫКА
}

\author{
И.Н. Цаллагова \\ E. Şahingöz
}

Одним из самых значимых и феноменальных явлений в области семантики слова и, в иелом, семантической системы любого языка, является полисемантизм. Вновь появляющзиея понятия и явления, вызывают необходимость в таксономических операциях и часто могут обозначаться уже существующим в языке словом, в котором пересекаются общзе черты этих понятий и явлений. Наиболее предрасположенными к образованию новых значений оказывается соматизмы, пласт лексики, обозначающий части тела человека и животного. Данная группа слов является одним из самых распространенных оббектов исследований сравнительно-исторического, структурно-сопоставительного и лингвокультурологического характера, вследствие своей универсальности и древности. Настоящяая статья посвящена исследованию семантической структуры полисемантов "скр/голова» и «згрдю/сердие» в дигорском варианте осетинского языка. В работе описаны основные характеристики значений слов, проанализирован характер их многозначности. Определена смысловая структура анализируемых лексем, а так же сбормулированы их первичные и вторичные значения. Опираясь на приведенные характеристики проведен компонентньй анализ значений полисемантов «скр/голова» $и$ «зердж/сердие». В ходе анализа выявлено, что в прочессе своего развития и преобразований первичных значений, анализируемье лексемы приобрели довольно большое количество переносных (вторичных) значений. Образование новых значений происходит с помощью метафорических, метонимических или функииональных переносов. Семантическая структура полисемантов сор/голова и зерде/сердие многообразна по своему плану содержания. Этим обусловлен тот бакт, что они являются компонентами множества идиоматических сочетаниц̆, фразеологизмов и сложных слов.

Ключевые слова: осетинский язык, дигорский вариант осетинского языка, лексика, семантика, лексико-семантическая система языка, соматизмы, полисеманты.

One of the most meaningful and wide-spread phenomenon in the field of semantics of words and, in general, semantic systems of any language is polysemantic nature of words. Emerging concepts and phenomena stimulate taxonomic activity of a language, and quite often they can be designated by an already existing word in the semantics of which the common features of these concepts and phenomena intersect. The most susceptible to the formation of new values is a group of the somatic terms, the layer of the vocabulary denoting human and animal body parts. This group of words is one of the most common objects of comparative historical, structural, linguistic, and culture studies, because of its universal and deep-rooted character. This article is devoted to the semantic structure of the polisemantic words 'sor/head' and 'zordo/heart' in Digor variant of the Ossetian language. The work describes the main characteristics of the meanings of these words that create the fundamental basis for analysis of the multiple meanings of particular words. The semantic structure of the lexemes is defined and their primary and secondary meanings are formulated. Based on the characteristics the componential analysis of polisemantic 'sor/head' and 'zordo/heart' is held. The analysis revealed that, in the course of its development and transformation of their primary meanings quite a number of figurative (secondary) values have evolved. The metaphoric, metonymic or functional changes result in acquisition of new meanings. The semantic structure of polisemantic soer/head and 
zoerdo/heart is diverse in its contents. This accounts for the fact that they are components of many idiomatic combinations, phraseological units and complex words.

Keywords: Ossetic language, digor Ossetian language variant, vocabulary, semantics, lexicalsemantic language system, somatizmy, polisemanty.

На сегодняшний день в центре внимания лингвистов находятся вопросы полисемии слова, так как данная проблема относится к числу самых важных в семасиологии. Довольно длительный период российские и зарубежные лингвисты исследовали вопросы, связанные с проблемами лексической семантики слов. Особое внимание уделялось способам и мотивации изменений значений слова, их сужение или расширение. Семантический аспект того или иного слова привлекал исследователей лишь в качестве иллюстративного языкового материала для различных целей. Однако в середине прошлого столетия в исследованиях начал подниматься вопрос о системном характере преобразований, происходящих в значении слова.

Употребление одного и того же слова в разных значениях является для человека естественной мыслительной операцией. Значения многозначного слова реально присутствуют в сознании. Человеческий мозг обладает способностью хранить достаточно большой информационный материал. При необходимости автоматически происходит реконструкция в сознании того фрагмента действительности, с которым связано одно из значений данного языкового знака, и, наоборот, носитель языка способен воспроизвести языковой знак, с которым сопряжен воспринимаемый фрагмент действительности. Собственно говоря, в этом и заключается психофизическая сторона полисемии слова $[1,5]$.

Р.Ю. Мугу утверждает, что значение слова, являясь связующим элементом между отображением его физического облика и соответствующего предмета действительности, автоматически реконструируется в сознании в момент воздействия на него языкового знака. Трансформацию значений лексем можно объяснить только в психофизическом аспекте. В качестве превалирующей причины возникновения многозначности выступает ментальный психофизический потенциал носителей языка, мобилизующийся посредством объективных социально-исторических изменений [1].

По степени многозначности к наиболее продуктивным слоям лексики следует отнести названия частей тела человека или животного, иначе говоря, соматизмы. Отношение соматизмов к самому древнему пласту словарного фонда любого языка не вызывает уже сомнений. Подтверждается это мнение и на основе данных осетинского языка. Этимология большинства терминов, обозначающих органы или части человеческого тела иранского происхождения. Следует так же отметить, что понятия «рука», «нога», «рот» имеют наряду с иранскими наименованиями ( $а р \mathcal{M}, \oint 6 а d, к о м)$ параллельный ряд неиранских, идущих из кавказского субстрата (къах, къух/къох, дзых/цъух). В речи, в свободном употреблении кавказские формы наиболее употребительны и практически вытеснили иранские. Но иранские формы «законсервированы» в сложных словах и сочетаниях, например, арм - жрходтюе (жрм + ходтю) букв. шапки для рук; жрдзжеб (жрм+дзжф) букв. ладоней удар; отбивание такта при танце; срмахур/къохахур - прирученный, жгомук - безголосый, немой; комикъолюе букв. стенка рта; внутренняя часть щеки; ияесгом (ияест + ком $)$ - букв. глаз рот; лицо; коммхе кжесун - букв. смотреть в рот; слушаться; фадигъолюе - букв. альчик стопы; щиколотка; фаднез - болезнь ног; фадат - букв. место для ноги; возможность и т.д. Таким образом, можно 
утверждать, что соматизмы относятся в основной словарный фонд осетинского языка, отличаются особой устойчивостью и повышенной активностью, как в словообразовании, так и в образовании новых значений [2].

Исследование соматической лексики дает возможность определить, каким образом воспринималась окружающая действительность носителями различных языков. Ведь человек именно с опорой на свой телесный опыт создает представление о мире. Во все времена окружающие предметы, понятия и явления наделялись человеком качествами, схожими с его телом.

Человек не только именует объекты окружающего мира с опорой на части своего тела, их признаки и функции, но и устанавливает пространственные ориентиры относительно себя. Практически во всех языках человек моделирует ориентацию предметов в пространстве, так сказать, по себе $[3,14]$.

В осетинском языке данный пласт лексики, а также вопросы полисемии недостаточно исследованы. В той или иной степени, данная проблематика затрагивалась исследователями осетинского языка [4; 5; 6; 7; 8]. Однако, специальных работ, посвященных значению слова, соматической лексике, в осетинском языкознании на сегодняшний день нет.

Данная статья посвящена исследованию семантической структуры полисемантов «скр/голова» и «зюрдю/сердие» в дигорском варианте осетинского языка.

В отечественной лингвистике описаны характеристики значений слов, которые способствуют глубокому анализу многозначности конкретных слов, и проведению компонентного анализа их значений $[9 ; 10 ; 11]$.

Компонентный анализ многозначного слова, предполагает определение следующих характеристик: 1) основное/неосновное; 2) свободное/связанное; 3) прямое/переносное; 4) нейтральное/стилистически-маркированное.

\section{Основное/неосновное значение слова.}

Е. Курилович пишет, что «главное значение то, которое не определяется контекстом, в то время как остальные (частные) значения к семантическим элементам главного значения прибавляют еще и элементы контекста» $[9,246]$. Основные значения более употребительны и менее зависимы от контекста, неосновные же наоборот, менее употребительны и практически всегда обусловлены контекстом.

\section{Свободное/связанное значение слова.}

Свободные и связанные значения противопоставлены друг другу. Свободные значения реализуются в самых разнообразных контекстах, а связанные связаны с конкретным типовым контекстом.

Прямое/переносное значение слова.

Полисемия обусловливает появление у слов прямых и переносных значений. Изначально, слово всегда однозначно. Новые значения, являются последствием переносного употребления слова, иначе говоря, в тех ситуациях, когда наименование одного явления, используется для наименования другого. Мотивацией переноса значений является сходство или смежность этих явлений. Именно этим и обусловлена связь значений многозначного слова между собой.

В этой связи, нужно отметить, что существуют два основных вида переносного значения - метафорический и метонимический. Метафорический перенос обусловлен схожестью предметов и связан со сравнением явлений. Новое значение слова в данном случае - результат ассоциативных отношений. Метонимический перенос - перенос наименования по смежности явлений, их взаимосвязи, например, пространственной, временной и т.д. Следует отметить, что разновидностью метонимии является синекдоха. Синекдоха часто фигурирует в образовании переносных значений у соматической лексики - когда названия целого используется для наименования частей целого, или наоборот [12]. 
Нейтральное/стилистически-маркированное значение.

Отнесенность к нейтральным или стилистически-маркированным значениям определяется таким образом - значения слов, без дополнительных эмоциональных смыслов, являются нейтральными, значения же в которых они имеют место быть, стилистически маркированы.

В качестве иллюстрации, мы проведем компонентный анализ значений соматизмов скр/голова и зердж/сердие в дигорском варианте осетинского языка. Данная задача осложнена тем, что на сегодняшний день имеется лишь один «Толковый словарь осетинского языка» под редакцией Н. Я. Габараева. К сожалению, из запланированных 4-х томов изданы только два, в 2007 г. вышел первый том (8 тысяч слов от А 一 Æ), в 2010 - второй том (8 тысяч слов от Б - Къ). Лексика дигорского варианта осетинского языка представлена в словаре выборочно [13].

Вследствие этого, нами даны собственные толкования рассматриваемых лексем. Выбор именно данных соматизмов продиктован тем, что лексемы сжр/голова и зюрдљ/сердце в осетинском языке относятся к имеющим наибольшее количество значений.

Анализ значений лексемы сюр/голова показал, что она включает в свою смысловую структуру такие семы, как: 1) думать, размышлять, мозг; 2) главный; 3) круглая форма; 4) верхняя, расположенная наверху (часть); 5) начало чего-либо.

Таким образом, соматизм сер/голова в осетинском языке (в обоих его вариантах) имеет такие значения, как:

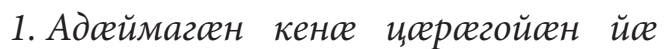
хъанз, кхесийне, игъоскен, аде сема смаг севзаржен оргентте кееи сенияе, еци баужри хай/Часть тела животного и человека, в которой находится мозг, органы зрения, вкуса, обоняния, слуха и рот (мже сжр рессуй/у меня болит голова; йю скркей йеу гъун джр куд нже фюегъгъжуа/пусть с его головы даже волос не упадет; ужйугбжл авд скри адтжй/у великана семь голов было и т.д.);

2. Естюей соеккаг хай/Верх, верхняя часть чего-либо (къљдзжхи сжр/вершина скалы; сехсири скртже/сливки, букв. верхушки молока и т.д.);

3. Аджймаги зунд, кемкн/Человеческий ум, рассудок, сознание (скргин аджймаг/букв. головастый, умный; ужззау скр аджймаг/букв. человек с тяжелой головой, степенный, вдумчивый человек; ржуюг скр аджймаг/букв. человек с легкой головой, перен. легкомысленный человек);

4. Гоймаг/Личность (не сортое нее барже нжбал жнцзе/букв. наши головы не принадлежат уже нам; мы сами себе уже не принадлежим; мюхе сюр дюу хузюн нж уарзтон/даже свою голову (самого себя) я не любил так как тебя; мж сжрбжл кжркдзей рамардтони, /убили друг друга ради меня и т.д.);

5. Естжй райдайжн/Начало чего-либо (дони скр/исток реки; хабжрттое скркй кжронмхе ракодта/рассказал все новости сначала до конца; радзурди сюр/начало рассказа и т.д.);

6. Ести оехгхнжн/Крышка, крыша (покрытие) (хжљзари скр/крыша дома; аги скр/крышка котла, казана; кири скр/крышка сундука и т.д.).

7. Ефсон, ангъосаг/Причина (хили скр/причина ссоры, драки и т.д.);

8. Фонс нимайуни еужг/Единица счета скота, животных (дюе скери скъюти/десять голов в хлеву и т.д.).

9. Тумбул хузи бахуюруйнаг/Пищевой продукт в круглой формы (цигъди скр/головка сыра; къабускайы скр/качан капусты и т.д.).

Слово скр в осетинском языке может выполнять роль послелога «на», «над», «поверху», «через» (мкргътюе скрти тюехунц, /птицы летят поверху; дони сюети хед/мост через реку и т.д.).

Семный состав соматизма зжрдж/сердце в осетинском языке следующий: 1) жизненно важный для че- 
ловеческого организма орган; 2) душа и чувства человека; 3) центральное расположение (в организме); 4) форма вытянутого овала, раздвоенного сверху, сужающегося книзу с острым вытянутым концом.

Соматизм зжрдж/сердце в осетинском языке (в обоих его вариантах) имеет такие значения, как:

1. Адсеймаги юма берюе ияеркгойти тогерзелоноен реуи галеуфарс ии сормагонд орган ес, ейю/Центральный орган кровеносной системы человека и многих живых существ в левой стороне грудной полости (зæрди гупn-гуnп/стук сердца, сердцебиение; зжрди фицдтк, тюетюе, ауиндзгутое/сердечные мышцы, жилы и т.д.);

2. Адюймаги аллихузон оенкъаронтке омма ахаститюе, уоди, равги, кеми символ/Этот орган выступает как символ души, переживаний, чувств, настроений (зюрдюмже и,жун/букв. «идти к сердцу»; нравиться; зердюбюл дарун/букв. «держать на сердце»; помнить; зжрди хатm/букв. «тип, вид сердца»; характер человека, нрав; зюрдюе ходуй/букв. «сердце смеется»; обижаться; хъюбкр зжрдж/букв. «твердое сердце»; бессердечный; зжрджргъюев/смышленый, способный; зжрдегенжй/от всего сердца и т.д.).

3. Гъуди, фюендон, федардзийнадж/Мысль, решимость, намерение, решение (йсе зюрди ес/букв. «в его сердце есть»; мысль, задумка; йюе зюрди атmжй/букв «у него было в сердце»; намерение, решение; бедарзюрдюе/букв. «крепкое сердце; с крепким сердцем»; смелость (смелый), храбрость (храбрый), стойкость (стойкий) и т.д.);

4. Ести фоеззинди, гъуддаги сойраг архайюг/Важнейшее место чего-нибудь, главное действующее лицо (гъуддагжн $\propto$ зюрдю/букв. «сердце дела»; вдохновитель, главное действующее лицо; Цъюй дон Цъжйы комь зюрдю (слова из песни)/Река Цейдон - сердце Цейского ущелья; Иристони зюрдю/букв. «сердце Осетии»; центр Осетии, самый главный район (ме- сто) Осетии; душа Осетии, символ души Осетии и т.д.);

5. Енгулдзи фюелмкендр сема рессагедюр бунат/Наиболее чувствительная часть пальца, мякоть на кончике пальца (юнгулдзи зюрдю; къохи зюрдю/букв. «сердце пальца»).

По мнению В.И. Абаева, идеосемантика соматизма «зæрдж/сердце» поистине необъятна. Она выходит далеко за пределы анатомии и физиологии и включает так же психическую сферу - все, что, скажем, в русском языке обозначается словом «душа», не только разнообразные эмоциональные, но даже интеллектуальные состояния и проявления, сознание, память. Почти все, что природа возложила на мозг и нервы, язык возложил на «сердце». Отсюда множество устойчивых сочетаний и сложных слов с словообразующим компонентом «зæрдæ» [14], например, зюрдже ивюрун/букв. «ставить сердце»; обещать, обнадеживать; ободрять; зюрдю дарун/букв. «держать сердце»; надеяться, считывать; подавать надежду; зюрдю жлхюнун/букв. «покупать сердце»; угождать, заискивать, добиваться расположения; задабривать; зюрдю зонун/букв. «знать сердце»; чувствовать, знать; зжрдж хессун/букв. «нести сердце»; тошнить; зюрдюмюе ияеун/букв. «идти к сердцу»; нравиться; зордюбюл дарун/букв. «держать на сердце»; помнить; зюрди хатm/букв. «тип, вид сердца»; характер человека, нрав;

зюеди медрахаст/букв. «мед- первая часть сложных слов со значением «внутри»; рахаст/поведение, повадка, положение, отношение; «внутреннее поведение сердца»; характер человека; зюрдюе ходун/букв. «сердце смеется»; обижаться; мюе зюрдюе дюе нюе есуй/букв. «мое сердце тебя не берет, не принимает»; ты мне не нравишься; мже зюрдюе ди исиььюх жей/букв. мое сердце от тебя стало серым, зеленым, голубым; ты надоел мне; зюрдюе сюетмнн/букв. «разбить, сломать сердце»; повергать кого-либо в отчаяние, безнадежность и т.д. 
Компонентный анализ значений лексем скр/голова и зкрдж/сердце, показал, что они имеют довольно развернутую семантическую парадигму. Для слова скр/голова основным значением является «часть тела животного и человека, в которой находится мозг, органы зрения, вкуса, обоняния, слуха и рот», а для лексемы зердюе/сердие - «центральный орган кровеносной системы человека и многих живых существ в левой стороне грудной полости». Данные значения описываемых соматизмов наиболее употребительны, а также не зависят от контекста, в котором они используются. Остальные значения характеризуются нами как неосновные, так как они требуют определенного контекста. Неосновные значения обладают общими семантическими признаками с основным значением, чем и обусловлена их взаимосвязь. Скажем, значение слова сюер/голова «человеческий ум, рассудок», связано с основным значением, семой «мозг». Кроме того, все значения имеют общую сему «верхняя часть». Значение лексемы зюрдж/сердие «важнейшее место чего-нибудь, средоточие, главное действующее лицо» и его основное значение связывает сема «центральный».

Значения лексемы скр/голова «верхняя часть тела человека», «часть тела животного и человека, в которой находится мозг, органы зрения, вкуса, обоняния, слуха и рот», «личность» являются свободными, так как они не требуют определенной сочетаемости, контекста. Все остальные значения мы относим к связанным, потому как для их реализации необходимо наличие типового контекста. Так, значение «человеческий ум, рассудок» требует обязательного присутствия характеризующего слова, роль которого чаще выполняет прилагательное (ужззау схр аджймаг/букв. человек с тяжелой головой, степенный, вдумчивый человек; рюуюг сюр адюймаг/букв. человек с легкой головой, перен. легкомысленный человек). Значение «крышка» чаще все- го употребляется в контексте определяющего слова в виде существительного в форме родительного падежа (хюдзари скр/крыша дома; аги сюе/крышка котла, казана; кири сюер/крышка сундука и т.д.). Анализируя значения слова зюрдж/сердце можно отметить, что свободными являются значения «центральный орган кровеносной системы человека и многих живых существ в левой стороне грудной полости», «орган выступает как символ души, переживаний, чувств, настроений» и «мысль, решимость, намерение, решение». Значения «важнейшее место чего-нибудь, средоточие, главное действующее лицо» и «мякоть на кончике пальца» требуют определенной сочетаемости. Так, слово зжедљ/сердце в значении «важнейшее место чего-нибудь, средоточие, главное действующее лицо» всегда сопутствуется словом-определителем, чаще всего это существительное в форме родительного падежа, например: Цъжй дон - Цъюйы комы зжрдже (слова из песни)/Река Цейдон - сердце Цейского ущелья; Иристони зюрдю/букв. «сердце Осетии», центр Осетии, самый главный район (место) Осетии, душа Осетии, символ души Осетии) и т.д.).

Следующая характеристика заключается в определении прямых и переносных значений. Основные значения всегда прямые, а неосновные могут быть как прямыми, так и переносными. За исключением первого основного значения, все остальные значения слова скр/голова имеют переносный характер, хотя степень и форма переносности у них различна. Так, значения слова сюе/голова «верх, верхняя часть чего-либо», «начало чего-либо», «крышка, крыша (покрытие)», «пищевой продукт в форме круга» заключают в себе метафорический перенос, так как перенос происходит на основе сходства признаков сравниваемых предметов (форма, функция, расположение). Значения «человеческий ум, рассудок, сознание», «личность», «причина», «единица 
счета скота, животных» метонимического характера, так как перенос происходит не по форме, а по смежности. К тому же значения «личность», «единица счета скота, животных» можно определить как синекдоху, иначе говоря, свойство слова называть и часть чего-либо, и целое.

Прямым значением слова зжрдж/сердце является его основное значение «центральный орган кровеносной системы человека и многих живых существ в левой стороне грудной полости». Все остальные являются переносными. В данном случае хочется отметить, что наиболее употребительно переносное значение «символ души, переживаний, чувств, настроений» так как именно в этом значении соматизм зерде/сердие становится компонентом большого количества идиоматических сочетаний и словообразований, которые мы уже приводили.

Многозначность лексем сор/голова и зордж/сердие основана на разнообразном плане содержания. Это подтверждается тем, что они входят в качестве образующего элемента во множество идиоматических сочетаний и фразеологизмов, сложных слов, которые часто не поддаются точному переводу: же сер ин радаста/букв. побрил ему голову (сильно отругал); мже скр мюбюл куройни зилд кенуй/букв. моя голова крутится на мне словно мельница (говорят о ситуации, когда много дел, проблем); сжрмхе хессун/букв. нести к голове (считать для себя подобающим, достойным, не унизительным, не брезгать, мириться), же скрбюл сюе систа/букв. поднял их на голове (говорят в ситуации, когда кто-то кого-то взбудоражил, привел в состояние хаоса); зердюе хюссун/букв. «нести сердце»; тошнить; зжрдихудm/букв. «смех сердца»; обида; зюрдюгъар/букв. «теплое сердце»; обморок, обморочное состояние и т.д.

Таким образом, анализируемые лексемы являются одними из самых многозначных в дигорском варианте осетинского языка. Компонентный анализ значений описываемых соматических лексем показал, что наряду с прямыми значениями, они образовали в результате своего исторического развития множество переносных значений, которые к тому же различны по своей степени и форме. Во первых, соматизмы скр/голова и зюрдю/сердие выполняют определенные реальные функции в человеческом организме, что и определяет их первичные (основные) значения. Во-вторых, сердие является средоточием различных чувств, эмоций и переживаний, а голова - ума, рассудка человека. В том случае, когда та или иная история вызывает у нас эмоции, волнение мы говорим: мюе зердюбюе бамбалдюй/букв. тронуло мое сердце; мюе зюрдюмюе багъартmа/букв. проникло в мое сердце. Особо сильные переживания, тоска или грусть характеризуются выражениями - зерди рист/букв. боль сердца; зюерде унгжг/букв. сердцу тесно. К тому же сердце является средоточием любви, можно даже сказать органом любви. Об этом говорят такие фразы, как зюрди хабжрттю/букв. дела, рассказы сердца; сердечные дела. Существуют так же ласковые обращения к объекту любви: мюе зюрдю/букв. мое сердце; мюе зюеди хъаппюе/букв. ядро моего сердца и т.д. О некоем противостоянии сердиа и головы говорит фраза - сюрой сагъюс

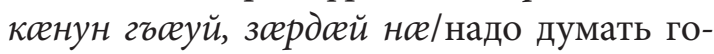
ловой, а не сердцем. В некоторых ситуациях соматизм голова так же отвечает за эмоциональное состояние, за проявление эмоций, например: мюе сюр мюбюл разилдюй дюу, ку фюейдтон/у меня закружилась голова, когда я тебя увидел; же сюр жруагъma/букв. опустил голову; взгрустнул и т.д. Полисемия рассматриваемых соматизмов в дигорском варианте осетинского языка многомерна. Расширение значений происходит путем метафорических, метонимических или функциональных переносов наименований, что говорит об ассоциативном характере взаимоотношений между сосуществующими значениями слова. 
1. Мугу Р. Ю. Полисемантизм соматической лексики (на материале русского и немецкого языков): Автореф. дис. ... канд. филол. наук. Майкоп, 2003.

2. Цаллагова И.Н. Семантическая и денотативная характеристика соматической лексики дигорского варианта осетинского языка // Известия СОИГСИ. 2017. Вып. 24 (63). С. 82-89.

3. Рахилина E. В. Когнитивный анализ предметных имен: семантика и сочетаемость. М., 2008.

4. Моргоева Л. Б. Паремии и речевые формулы осетинского языка: семантический, прагматический и этнолингвистический аспекты. Владикавказ, 2015.

5. Моргоева Л. Б. Экспрессивные грани слова: семантика и прагматика. Владикавказ, 2006.

6. Парсиева Л. К., Гацалова Л. Б. Активные процессы в языковой системе // Фундаментальные исследования. 2008. № 4. С. 79.

7. Парсиева Л. К., Гацалова Л. Б. Краткий очерк истории осетинской лексикологии // Вестник Владикавказского научного центра. 2013. Т. 13. № 1. С. 7-11.

8. Техов Ф. Д. Названия растений в осетинском языке. Цхинвал, 1979.

9. Курилович Е. Заметки о значении слова // Очерки по лингвистике. М., 1962. C. 237-250.

10. Шмелев Д. Н. Проблемы семантического анализа лексики М., 1973.

11. Стернин И. А. Лексическое значение слова в речи. Воронеж, 1985.

12. Фокина A. А. Роль соматических компонентов голова/вуй/head в формировании тематических групп фразеологических единиц (на материале русского, марийского и английского языков) // Филологические науки. Вопросы теории и практики. 2014. № 6 (36): в 2-х ч. Ч. II. С. 195-199.

13. Толковый словарь осетинского языка/Под ред. Н.Я. Габараева. М., 2007. T. 1; M., 2010. T. 2.

14. Абаев В. И. Историко-этимологический словарь осетинского языка. Т. І. М.-Л., 1958. Т. II. Л., 1973. Т. III. Л., 1979. Т. IV. Л., 1989. Указатель. М., 1995. 